\title{
Lysosomal or brush border enzymuria in kidney enzyme activities in seronegative rheumatoid arthritis
}

\section{Dejan Spasovski}

University Clinic for Rheumatology, faculty of medicine, University Clinical Center "Mother Therese", Skopje, Republic of North Macedonia. Corresponding Author: Dejan Spasovski, University Clinic for Rheumatology, faculty of medicine, University Clinical Center "Mother Therese", Skopje, Republic of North Macedonia.

Received date: December 04, 2020; Accepted date: December 19, 2020; Published date: December 28, 2020

Citation: Spasovski D., (2020) Lysosomal or brush border enzymuria in kidney enzyme activities in seronegative rheumatoid arthritis. $J$, Biotechnology and Bioprocessing 1(3); DOI:10.31579/2766-2314/019

Copyright: () 2020, Dejan Spasovski, This is an open access article distributed under the Creative Commons Attribution License, which permits unrestricted use, distribution, and reproduction in any medium, provided the original work is properly cited.

\begin{abstract}
Introduction: To determine the effects of non-treated seronegative rheumatoid arthritis (RA) on proximal renal tubule, sensitivity of Alanine aminopeptidase (AAP), $\gamma$-glutamyltransferase ( $\gamma$--GT), $\beta 2$ microglobulin in urine $\beta 2 \mathrm{M})$, as well as relation with rheumatoid factor (RF) and C-Reactive protein (CRP), DAS 28 disease activity index.

Methods: RF was determined by agglutination test (Latex RF test, while kinetic methods were used for determination of Alanine aminopeptidase (AAP) and $\gamma$-glutamyltransferase $(\gamma$-GT), as well as MEIA (Micro particle Enzyme Immunoassay) to determine $\beta 2$ microglobulin in urine. Samples (serum and urine) of 70 participants were examined (35 RA not treated, 35 health control group).

Results: In 35 RF negative RA, AAP enzymuria was present in $12(34.28 \%)$ patients, $\gamma$-GT was present in 7 patients $(20 \%)$, while $\beta 2$ microglobulin was present in 3 patients $(8.57 \%)$. In the healthy control group, 4 patients showed AAP positivity (11.42\%), 2 patients $\gamma$-GT positivity (5.71\%) and 1 patient showed presence of $\beta 2$ microglobulin in urine (2.85). RF was not present in any patient $(0 \%)$.

Conclusion: AAP has a higher sensitivity of $\gamma$-GT and $\beta 2$ microglobulin in the detection of asymptomatic renal lesions in non treated seronegative RA.

Keywords: alanine aminopeptidase, (AAP); $\gamma$-glutamyl transferase $(\gamma-$-GT), $\beta 2$ microglobulin $(\beta 2 \mathrm{M})$; rheumatoid arthritis (RA), rheumatoid factor (RF)
\end{abstract}

\section{Introduction}

Enzymes in urine can derive from plasma, glands of the urogenital tract, epithelial cells of the urinary tract, leukocytes, and erythrocytes [1] and kidneys. There are about 40 different enzymes [2-6] in the urine that belong to different groups: oxidoreductase, transferase, hydrolase, lyase, while isomerases and ligases are not found in the urine. The occurrence of such large number of enzymes in the urine indicates the dominant role of kidneys in their excretion.

Examination of the cell membranes of the brush epithelium of the proximal tubules confirms the localization of alanine aminopeptidase

(AAP) in $90 \%$, alaline phosphatase $(\mathrm{AF})$ in $70 \%$ and $\gamma$-glutamyl transpeptidase $(\gamma-\mathrm{GT})$ in $50 \%$ of the total activity of these enzymes in the kidney [7-9].

\section{Aim}

The aim of this study is to determine the effects of non-treated Rheumatoid arthritis on the tubular function AAP, $\gamma$-GT and $\beta 2 \mathrm{M}$ being used as indicators for proximal tubular damage.

\section{Materials and methods}

In patients included in the study, disease diagnose is based on the revised diagnostic criteria for classification of Rheumatoid arthritis proposed in 1987 by the American Rheumatism Association (ARA) [10-13]. For the classification, i.e. the patients to be included in the RA group it is necessary to satisfy at least 4 of the predicted 7 criteria.

Criteria from 1 to 4 were present at least 6 weeks. The study included 35 patients (age 28, age 7) who were diagnosed with seronegative RA, as well as 35 patients (age 18, age 17) as a healthy control group. The average mean age was 48.5 years $( \pm 4.13)$ (37-65 years) for the RA group, 36.2 years $( \pm 10.78)(29-65)$ for the healthy group. The average time of onset of disease in months from the beginning was $14.97( \pm 15.23)$, in the interval of (1-14) months. None of the patients in the study had a history of previous or current renal impairment. The others negate use of other drugs before sample were taken. The samples were collected in a period of 1 year.

\section{Including criteria}


In the study were included patients with RA at the age of 18-65 years, who were not previously treated with NSAIDs or DMARDs.

\section{Excluding criteria}

In the study were excluded patients with symptoms or conditions that can directly or indirectly affect the results, such as:

1. Patients with a history of gonorrhoea, mild to moderate hepatic, renal, hematologic, cardiovascular, neurological diseases, nausea, vomiting, autoimmune disease.

2. Patients with diabetes mellitus, acute infections, malignant neoplasms, febrile conditions.

3. Patients with urinary tract arthritis, urinary tract infections, SLE, mixed connective tissue disease, vasculitis.

4. Patients with a history of blood transfusion, and excessive body weight.

5. Patients who receive baseline therapy are excluded from the study.

6. Patient with a history of glycaemia or increased levels of product degradation in the 0 -th range: serum creatine and urine, serum urea, hypertension, arterial hypertension and hematological and enzyme status.

7. Patients previously treated with salicylates, antibiotics, gold salts, or diuretics.

All participants voluntarily took part in this study, so that the criteria to do it are met.

\section{Clinical assessment of disease activity}

Clinical assessment and interpretation was made from the subspecialist in the given area. The disease activity was assessed using DAS 28 index. (Disease Activity Score (DAS 28)) [14]. Indexes use mathematical formula to use the unique composite quantitative score consisting of palatable painfully sensitive joints (maximum number 28) and swollen joints (maximum number 28), global assessment for disease activity ( 0 $100 \mathrm{~mm}$ Visual Analog Scale VAS), as well as morning stiffness (minutes). DAS 28 index ranges from 0 to 10 and score below 3.2 qualifies the disease as low active.

\section{Laboratory assessment}

For clinical assessment of disease, it is necessary to consider the following laboratory variables: Complete blood count (CBC) and differential, acute phase reactants, such as C-reactive protein (CRP), Rheumatoid factor (RF), Erythrocyte sedimentation rate (ESR), alkaline phosphatase (AF), aspartate aminotransferase (AST), alanine aminotransferase (ALT), creatine kinase (CK), lactate dehydrogenase (LDH), urea / serum, creatinine / serum.

Urine samples were taken not only for rutine urinary examination, but also for determination of AAP, $\gamma$-GT, $\beta 2 \mathrm{M}$.

Serum urea is determined by the method of "Kassirer"

Reference values: Serum urea (3-7.8 mmol / L).

Creatine in serum and urine and determined by the method of: "Jaffe"

Reference values: Serum creatine $45-109 \mu \mathrm{mol} / \mathrm{L}$; Creatine in urine 7 $17 \square \mathrm{mol} / \mathrm{dU}$.

C-reactive protein (CRP) determined by agglutination test (Latex CRP test)

Reference values: < $6 \mathrm{mg} / \mathrm{L} \mathrm{CRP}$ in serum

Rheumatoid factor (RF) determined by agglutination test (Latex RF test)
Reference values: $<8 \mathrm{IU} / \mathrm{ml}$ in serum

Determination of Alanine Aminopeptidase Activity (AAP): Kinetic Method

Reference values: AAP in urine 0.25-0.75 U / mmol creatinine

Determination of $\gamma$-glutamyltranspeptidase $(\gamma$-GT) activity: Ifcc method Valuable referents

$\gamma$-GT (urine) $0.84-1.80 \mathrm{u} / \mathrm{mmol}$ creatinine

Determination of $\beta 2$ microglobulin $(\beta 2 \mathrm{M})$ concentration in urine by the method "meia" ("micro particle enzyme immunoassay")

Reference values:

$\beta 2$ microglobulin (urine) $=0.02-0.19 \mathrm{mg} / \mathrm{L}$

\section{Statistical analysis}

For testing the significance of the differences between two arithmetic means, i.e. the corresponding proportions, the Student t-test is used, when comparing the mean values of the given number of parameters between two groups, such as Wilcoxon- matched test for independent samples. Sensitivity and productivity for positive and negative tests of the examined markers is determined with tests for sensitivity and specificity. The $P$ value of between 0.05 and 0.1 is considered statistically significant. The data processing is made with the statistical package Statistical 7.0.

\section{Results}

In the group of 35 patients with RA, RF seronegative RA, AAP enzyme was present in $12(34.28 \%)$ patients, $\gamma$-GT was present in 7 patients (20\%), while $\beta 2$ microglobulin in urine was not present at all $(0 \%)$.

In the healthy control group, 4 patients showed AAP positivity (11.42\%), 2 patients $\gamma$-GT positivity $(5.71 \%)$ and 1 patient presented with $\beta 2$ microglobulin in urine (2.85). RF was not present in any patient $(0 \%)$

\section{AAP, $\gamma$-GT, $\beta 2 M$ and DAS 28 Index of Disease Activity}

In the group of 35 patients with RA, DAS $28>3.2$ was present in 28 patients $(80 \%)$.

In these 28 patients DAS $2>3.2$, AAP positive $10(35.71 \%)$ and their $\mathrm{M}$ $\pm \mathrm{SD}(1.25 \pm 0.43)$ range $(0.85-2.46), \gamma$-GT positive were $5(17.85 \%)$ their $\mathrm{M} \pm \mathrm{SD}(2.65 \pm 0.46)$ range $(0.95-3.45)$, while $\beta 2 \mathrm{M}$ was not present in any patient.

In 7 seronegative RF patients with DAS $28<3.2(20 \%)$. In these 7 patients DAS $28<3.2$, AAP was positive in 2 patients $(28.57 \%)$ and their $\mathrm{M} \pm \mathrm{SD}$ $(1.20 \pm 0.49)$ range $(0.80-2.30), \gamma$-GT positive in 2 patients $(28.57 \%)$ and their $\mathrm{M} \pm \mathrm{SD}(2.50 \pm 1.07)$, range $(0.90-2.20)$. $\beta 2 \mathrm{M}$ was not present in any patient.

1. Seronegative RF patients with DAS $28>3.2$ have higher AAP values than RF seronegatives with DAS $28<3.2$. $(1.25( \pm 0.43)$ vs $1.20( \pm 0.49)$, that had lower DAS 28 index. Between these 2 groups of AAP there was not statistical correlation ( $\mathrm{p}=0.185017)$;

2. Seronegative RF patients with DAS $28>3.2$ have slightly higher value of $\gamma$-GT than RF seronegative with DAS $28<3.2$. $(2.65 \pm 0.46)$ vs $(2.50 \pm 1.07)$. Between these 2 groups of $\gamma$-GT there was not statistical correlation ( $\mathrm{p}=0.670077)$; This group had larger $\gamma$-GT induction than the seronegative RF patients with DAS $28<3.2$. Graph 1 

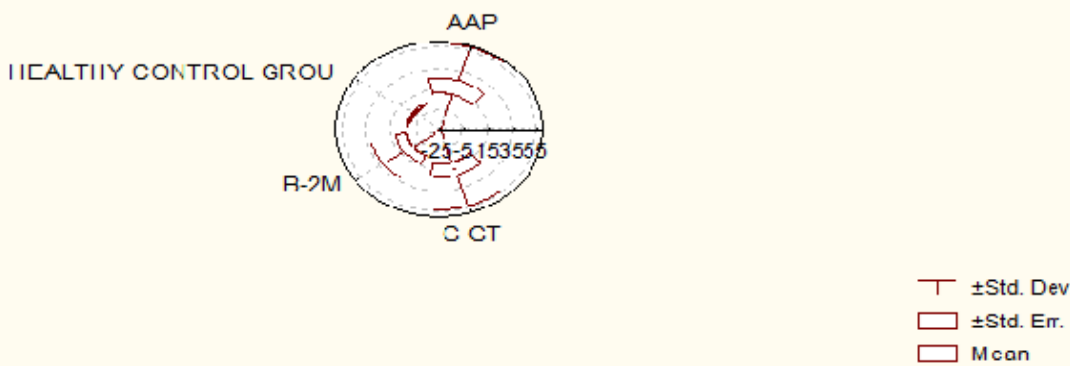

Graph 1. Distribution of aline aminopeptidase (AAP), $\gamma$-glutamyl transferase $(\gamma$-GT), $\beta 2$ microglobulin (urine) in Rheumatoid arthritis

\section{Discussion}

In standard medical rheumatology, the greatest emphasis is put on Rheumatoid arthritis as the most exposed disease. Seronegative RA is a rare form, difficult to recognize and most often confused with degenerative rheumatism, probably due to their frequency.

Urinary enzyme activity is normally low in the urine and increases when renal tubular cells are excreted [15]. Urinary enzymes, especially NAG, $\mathrm{AAP}$, and AF are very sensitive indicators of parenchymal renal damage in comparison with functional measurements such as glomerular filtration rate (GFR), creatinine and inulin clearance. The relatively low sensitivity of the GFR can be explained by the large renal functional reserve and its large capacity for compensation [16]. There are indications that elevations in urinary enzyme activity may indicate the location of the primary renal tubular damage due to their localization in the brush border area (microsomal AAP) and tubular lysozyme (NAG). They can be used in early diagnosis of acute renal failure because nephrotoxicity is induced by immunosuppressive drugs, contraceptives, antibiotics and cadmium exposure [17-19].

The sensitivity of AAP is higher in comparison with $\gamma$-GT and $\beta 2 \mathrm{M}$. Other standard routine tests used to assess renal function show low sensitivity: creatine in serum and urine, urea in serum. Seronegativity has an impct on the occurrence of AAP enzymuria. This is also present for seronegative patients with DAS $28>3.2$ who have a much larger AAP induction than DAS $28<3.2$. Statistical correlation of disease duration in months indicates that the non-treated RA affects kidney tissue as one of the visceral manifestations of disease.

Non-treated RA primarily affects tubular brush border area and enzymes that derives from this area have increased sensitivity.

\section{Conclusion}

AAP has a higher sensitivity than $\gamma$-GT and $\beta 2 \mathrm{M}$ in the detection of asymptomatic renal lesions in the non-treated seronegative RA. AAP and $\gamma$-GT can be used in the everyday clinical practice to diagnose early, asymptomatic renal lesions.

\section{References}

1. Chiu JSP. (1994) Models used to assess renal function. Drug Devel Res. 32:247-55.

2. Portman RJ, Kissane JM, Robson AM (1986) The use of beta 2microglobulin to diagnose tubular injury in pediatric renal disease. Kidney Int 30:91-98.
3. Hong CY, Chia KS. (1998) Markers of diabetic nephropathy. $J$ Diabetes Complications. 12:43-60

4. Sherman RL, Drayer ED, Leyland-Jones BR et al. (1983) NAcetyl-b-glucosaminidase and b-2 microglobulin. Arch Intern Med.143:1183-5.

5. Hultberg B, Ravnskov U. (1981) The excretion of N-acetyl-betaglucosaminidase in glomerulonephritis. Clin Nephrol. 15:33-8.

6. Johnston IDA, Jones NF, Scoble JE, Yuen CT, Price RG. (1983) The diagnostic value of urinary enzyme measurements in hypertension. Clin Chim Acta. 133:317-25.

7. Sanberg T, Bergmark J, Hultberg B, Jagenburg R, Trollfors B. (1986) Diagnostic potential of urinary enzymes and beta-2microglobulin in acute urinary tract infection. Acta Med Scand. 219: 489-95.

8. Betha M, Forman DT (1990) Beta-2-microglobulin: a significance and clinical usefulness. Ann Clin Sci. 163-168.

9. Well wood JM, Ellis BG, Price RG, Hammomd Thompson AE, (1975).Using N-acetyl Beta-D-glocosaminidase activities in patients with renal disease. Brit Med J 139:408

10. Sherman RL, Drayer ED, Leyland-Jones BR et al. (1983) NAcetyl-b-glucosaminidase and b-2 microglobulin. Arch Intern Med. 143:1183-5.

11. Arnett FC,Edworthy Sm,Bloch Da,McShane DJ,Fries JF,Cooper NS, et al. (1988) The American Rheumatism Association 1987 revised criteria for the classification of rheumatoid arthritis. Arthritis Rheum. 31:315-24.

12. Van Gestel AM, Prevoo MLL, van't Hof MA, van Rijswijk MH, van de Putte LBA, van Riel PLCM. (1996) Development and validation of the European League against Rheumatism response criteria for rheumatoid arthritis. Arthritis Rheum. 39:34-40.

13. Prevoo ML, van't Hof MA, Kuper NH, van Leeuwen MA, van de Putte LB, van Riel PL. (1995) Modified disease activity scores that include 28 -joint counts. Development and validation in a prospective longitudinal study of patients with rheumatoid arthritis. Arthritis Rheum. 38: 44-8.

14. Balsa A, Carmona L, González-Álvaro I, Belmonte MA, Tina X, Sanmartí R. (2004) Value of DAS-28 and DAS 28-3 as compared to ACR-defined remission in rheumatoid arthritis. $J$ Rheumatol. 31:40-6

15. Prevoo MLL, van Gestel AM, van't Hof MA, van Rijswijk MH, van de Putte LBA, van Riel PLCM. (1996) Remission in a prospective study of patients with rheumatoid arthritis. American Rheumatology Association preliminary remission criteria in relation to the disease activity score. Br J Rheumatol. 35:1101-5.

16. Maruhn D, Paar D, Bock KD. (1979) Lysosomal and brush border membrane enzymes in urine of patients with renal artery stenosis and with essential hypertension. Clin Biochem. 12:228-30. 
17. Johnston IDA, Jones NF, Scoble JE, Yuen CT, Price RG. (1983) The diagnostic value of urinary enzyme measurements in hypertension. Clin Chim Acta. 133:317-25.

18. Clinical practice guidelines for chronic kidney disease: evaluation, classification and stratification. Am J Kidney Dis (2002); 39(Supp11):S1-S266.

19. Williams RC, Nissen MH, Malone CC (1993) Rheumatoid factor from patient with rheumatoid arthritis react with Des-Lus ${ }^{58}$ - beta- 2m, modified beta-2-microglobulin. Clin Exp Immunol 92: 41924.

20. Viergever PP, Swaak AJG. (1989) Urine-and serum beta-2 microglobulin in patients with rheumatoid arthritis: a study of 101 patients without sign of kidney disease. Clin Rheumatol. 8:36874. 